This is an electronic reprint of the original article. This reprint may differ from the original in pagination and typographic detail.

Author(s): Luoma-aho, Vilma; Tirkkonen, Päivi; Vos, Marita

Title: $\quad$ Monitoring the issue arenas of the swine-flu discussion

Year: $\quad 2013$

Version:

Please cite the original version:

Luoma-aho, V., Tirkkonen, P., \& Vos, M. (2013). Monitoring the issue arenas of the swine-flu discussion. Journal of Communication Management, 17(3), 239-251. https://doi.org/10.1108/JCOM-11-2010-0069

All material supplied via JYX is protected by copyright and other intellectual property rights, and duplication or sale of all or part of any of the repository collections is not permitted, except that material may be duplicated by you for your research use or educational purposes in electronic or print form. You must obtain permission for any other use. Electronic or print copies may not be offered, whether for sale or otherwise to anyone who is not an authorised user. 


\title{
Monitoring the issue arenas of the swine-flu discussion
}

\author{
Vilma Luoma-aho, Päivi Tirkkonen and Marita Vos
}

\begin{abstract}
Purpose - This paper seeks to describe the changing organizational environment and stakeholder debate currently taking place in various 'issue arenas' during a crisis. Organizations today need to find and monitor these arenas before being able to communicate with their stakeholders.
\end{abstract}

Design/methodology/approach - Communications of authorities and discussions by citizens are studied and analyzed in a case study related to the 2009 swine flu or influenza A (H1N1) episode in Finland. The organizational point of view is studied through media releases of the National Institute for Health and Welfare (THL), and the citizen point of view through a content analysis of popular discussion online forums through which the authorities attempted an intervention.

Findings - The analysis of the media releases revealed that the crisis communication of the authorities was timely and factual, yet failed both in using understandable concepts and responding to the emotional needs of people threatened by swine-flu and questioning the safety of the vaccination. These deficiencies intensified emotion-driven discussion, and when people opposed to vaccination managed to secure the central 'issue arenas' using the words 'swine flu' online, this led to online speculations and exaggeration of threat, excluding the authorities and logical argument from the discussion.

Research limitations/implications - This study only looks at the swine-flu debate from the points of view of the authorities and citizens, and does not discuss the role of the legacy media, for example. Since this study focused on one country, a global comparison could be the next step.

Practical implications - This study argues that success in communication today depends heavily on using the right language, finding the right issue arenas, getting there early, and answering the needs raised in those arenas. It is crucial for authorities as well as public relations practitioners to acknowledge these changes in communication in order to be able to deliver their messages.

Originality/value - The concept of issue arenas can help to clarify changing perspectives in communication management. Moreover, the study is timely as it focuses on a global topic pandemics and their communication. The results demonstrate how lack of monitoring and belated activity may lead to online issue arenas being dominated by extreme groups, who then strongly shape public opinion. Practitioners and scholars need to focus on identifying issues and stakeholder needs, and to understand the dynamics of the arenas concerning them.

Keywords - Issue arenas, social media, authority communication, health communication. Paper type - Research paper 


\section{INTRODUCTION}

The central role of public relations and communication with stakeholders during times of crises has previously been established (Coombs, 1999; Coombs \& Holladay, 2008; Reynolds, 2006; Rowan, 1991). In general it has been suggested that public relations co-creates shared social meaning and hence facilitates cooperation (Heath, 2006). The bridging role of communication (Grunig, 2006) is especially important during times of heightened risk or crises.

The traditional organization-centred type of thinking is becoming outdated as interaction with and among stakeholders moves onto new stages facilitated by technology and the social media. We call these dynamic stages of interaction and discussion 'issue arenas' (Luoma-aho \& Vos, 2010). These new stages sometimes complement the traditional or legacy media, but at times they take over as central arenas for certain topics. The new media are also relevant as journalists use social media not only for communication but also as sources (Miel \& Faris, 2008).

To promote shared understanding and to network and negotiate in such a complex and diverse external environment, organizations need to nurture polyphony and diversity in their internal environment (Christensen et al., 2005; Christensen et al., 2008). Organizations have to be aware of and be able to interpret various environmental stimuli (Sutcliffe, 2001). This in turn, requires a process for monitoring ongoing developments in the organizational environment. It is not enough to monitor the perception of current issues at a distance; instead, active participation in the debate helps organizations to keep track of changing points of view in both the physical, traditional media as well as in the new, virtual media. Therefore, the concept of issue arenas can help clarify changing perspectives in public relations.

This paper focuses on issue arenas and their function during times of heightened risk and crises. The paper is organized as follows. First the idea of issue arenas is introduced on the conceptual level during crises. Second, the need for heightened monitoring is argued. Third, these ideas are tested through a case study of the communication surrounding the 2009 swine flu epidemic, also called influenza $\mathrm{A}(\mathrm{H} 1 \mathrm{~N} 1)$, in Finland, from the point of view both of the authorities and of individual citizens. To sum up the results, the issue arena of the swine flu debate in Finland is mapped, and the results and their implications are discussed. To conclude, the limits of the study are discussed along with the implications of the findings for the field of public relations and crises communication.

\section{FROM ORGANIZATIONAL CONTROL TO ISSUE ARENAS}

The traditional model of communication, where the organization is mapped as the central player, is quickly becoming outdated with the advent of new and social media. The organizational environment is not static, but is characterized by a constant conflict of interests. The stakeholder environment (Mitchell, Agle \& Wood, 1997) constitutes the ecosystem in which organizations operate, and thus far its representation in models has failed to match the dynamic nature of current 
communication ( $\mathrm{Wu}, 2007)$. What is needed is a more dynamic description of the stakeholder field of forces in which today's organizations function.

It would be misleading to think of stakeholders as only having a stake in an organization; instead, both the organization and different stakeholders can be addressed via issues that both have a stake in. Hence the trend is moving away from organizational control toward the place where issues are being discussed. We call these real or virtual places in which topics of shared interest are discussed 'issue arenas' (Luoma-aho \& Vos, 2010). In these arenas, organizations are viewed by different stakeholders which leads them to present their best assets through, for example, impression management and framing (Goffman, 1974; Johansson, 2007; Hallahan, 1999). According to Cammaerts (2007) these fragmented arenas show opposing and conflicting discourses, ideas and interests. This includes displays of subtle forms of power when organizations engage in talks and negotiations within a crowded message environment (Cheney \& Christensen, 2006).

Issue arenas are like stages or platforms (Goffman, 1959) in virtual and tangible surroundings. The scenery changes continuously as a result of interactions between the players and developments in the social environment. Issue arenas function as spaces for enactment (Weick, 2001) and facilitate stake exchange (Heath, 2006). Individuals and organizations might be more or less actively involved, but if the issue is related to the organization, it must take part.

In issue arenas, the ideas and issues discussed are themes in which both stakeholders and the organization have interests. The potential actors for both arenas on an issue are several, and depending on their timing and stance they either mount the stage and have a say on the issue, or are left in the audience (Luoma-aho \& Vos, 2009). Should an organization fail to give its point of view, other stakeholder opinions quickly dominate the arena, e.g. in the case of anti-corporate movements composed of distinct groups that dynamically unite and join large-scale campaigns (Karagianni \& Cornelissen, 2006). The role of public relations is to maintain the public discourse (Heath, 2006), as the debate might otherwise be highjacked by extreme stakeholders, which hinders problem solving and collaboration with others. Moreover, organizations have to live up to expectations (Wan \& Schell, 2007) and demands may rise during times of heightened risk and crisis.

\section{ISSUE ARENAS IN TIMES OF HEIGHTENED RISK AND CRISIS}

This paper focuses on issue arenas and their function during times of heightened risk and crisis. A risk can be defined as "a situation or an event where something of human value (including humans themselves) is at stake and where the outcome is uncertain" (Rosa 2003; 56). A crisis, on the other hand, refers to an event which can threaten human beings and organizations, their values (Rosenthal and Kouzmin, 1997), or their credibility or reputation (Howell and Miller, 2006). Crises can also exist in cyberspace, where rumours spread easily and accusations can be made against brands, organizations or individuals (Millar and Heath, 2004) which are not usually life-threatening.

Public health crises are usually concerned with epidemics of infectious diseases or the recognition of risks deriving from the environment or personal lifestyle (Reynolds and Seeger, 2005). At best, efficient risk and crisis communication can guide different stakeholders to work well 
together (Reynolds, 2006). Good risk communication should build trust in the communicator, create awareness, improve understanding, and motivate preventive action (Rowan, 1991) Moreover, risk communication can prevent a crisis from escalating. In crisis situations, the purpose of communication is to prevent or reduce the negative consequences of the crisis, and to defend people and organizations from damage (Coombs, 1999). The dynamics of constantly evolving issue arenas are especially visible during times of crises, when decisions are made quickly and information needs increase. Crises are also times when there is a heightened need for monitoring the dynamic enviroenment.

\section{MONITORING}

Monitoring refers to the analytical review and evaluation of changes (Vos \& Schoemaker, 2006). Environmental monitoring includes trends in public opinion and events in the socio-political environment to identify in what direction developments are proceeding and what needs increased attention (Pavlik, 1987; Sumser, 2001). The process can be more or less self-referential; as Cheney and Christensen (2006) suggest, it is often, from the organisation's perspective, to confirm existing practices rather than to be open to new points of view. The social media environment requires constant monitoring and study to detect and interpret any weak signals..

The results of monitoring may lead to participation in the relevant arena debates, or it may lead to the organization making changes to adapt itself to the environment. Grunig (2006) advocates communication as a bridging activity, in which organizations build linkages with stakeholders to constitute the organization in new ways, rather than using it as a buffering activity in order to justify the organization. Flynn (2006) suggests a multidimensional perspective where dialogue, collaboration and negotiation with multiple stakeholders occur simultaneously, the purpose being to maintain a balance zone, an equilibrium that satisfies mutual interests. This complexity calls for a different approach, one that is not just about seeing who is affected by the organization or who wants to affect it (Freeman, 1984), but rather about asking strategic questions such as "What is the best arena for interaction with this specific group? and "How can we prevent the debate from being hindered by the extreme views of one of the actors?" Such strategically proactive questions are well suited to a dynamic organizational environment embracing new forms of interaction such as the various new and social media and the requirement for greater need of interaction.

\section{ILLUSTRATIVE CASE: SWINE FLU}

During the year 2009, national administrations and the World Health Organization faced formidable challenges in answering the heightened need for information during the health risks associated with swine flu. People's perceptions of risk are not only based on rational arguments, but emotions greatly shape perceptions (see Loewenstein et al. 2001). In the light of this, communication by those in authorities should not ignore emotions and focus on the provision of facts only. 
Timely communication is central before and during a crisis (Avery \& Kim, 2009). In some cases poor communication can make a crisis worse, as in the case of avian flu at the Centre for Disease Control and Prevention (Avery \& Kim, 2009), where information about how the disease spreads was not communicated clearly.

The first signs of the swine flu crises were apparent at the end of April 2009 in Mexico, and while the first cases in Finland were reported within a few days of people returning from visits to Mexico, it was only in the autumn of that year that the pandemic hit Europe and Finland. The first wave was over by January 2010 and a next wave expected at the beginning of 2011.

The National Institute for Health and Welfare (THL) played a central role in Finland during the pandemic and local epidemics. Communication during the crisis was under the supervision of the Ministry of Social Affairs and Health (STM) in collaboration with THL. The first media releases about the disease were sent off in the spring of 2009, referring to the disease as swine flu. Interestingly, owing to international preferences, during the summer of 2009 WHO advised the National Institutes against using the concept 'swine flu', and instead proposed that only the correct term, Influenza A(H1N1), be used. This explains why neither the institute (THL) nor the ministry (STM) bought Internet addresses using the words swine flu. This, alas, turned out to be detrimental to individuals in need of information and vaccinations later on. Swine flu addresses were bought by activist groups opposing vaccination, natural product representatives, companies and NGOs. Thus they were able to take over the existing issue arenas and rank well in search engines (rokoteinfo.fi, sikainfluenssa.fi), turning national opinion against vaccination and the authorities.

\section{COMMUNICATION OF THE AUTHORITIES}

THL's communications were studied through a theory-based content analysis (Tuomi \& Sarajärvi, 2002) of all media releases produced during the swine flu episode. Between April 2009 and February 2010, a total of 73 media releases were issued (available online at www.thl.fi). The media releases were timely and correct, used $\mathrm{A}(\mathrm{H} 1 \mathrm{~N} 1)$ as a label instead of 'swine flu' and didn't show empathy, emotion or reaction to the human side of the crises. Citizens could not access the official releases through search engines. The end-result of the vaccination campaign was that less than half the population was vaccinated during the episode, although the aim was total coverage.

\section{METHODOLOGY}

To understand what citizens thought and felt about the topic, an analysis of discussion forums in Finland was performed. The reasons for participating in online discussions range from willingness to debate, disclosing of membership of a certain group, to expressing and obtaining social support and gathering information such as answers to questions (Welser, Gleave, Fisher and Smith, 2007). Therefore, online discussion forums provide a comprehensive view of people's topics of high interest. 
Two forums were chosen in which STM made an intervention during the epidemic: Iltalehti and KaksPlus. Iltalehti is the second biggest Finnish tabloid, whose online discussion forum is very actively used. KaksPlus is a family magazine, with an emphasis on prenatal and parenthood issues. For its interventions STM chose Iltalehti because of its wide readership and KaksPlus due to its central target groups, those most severely threatened by swine flu: pregnant women and families with small children.

The purpose of the study was to find out which issues related to swine flu interested citizens, how the authorities were discussed, what attitudes people harboured towards them and whether the interventions by STM affected the content of the debate. The study was carried out during the period March - May 2010. All 19 discussions in which STM participated were analyzed. The discussions were found using the search field in the forums. STM used only one pseudonym "STMinfluenssainfo" (STM influenza-info), thus discussions were easy to identify. In Iltalehti's online forum, a separate section, containing 2320 discussions, was dedicated to swine flu-related topics. In KaksPlus there was no such section, and 199 discussions were found via search engines (Google, Bing). STM participated in 19 (0.4 per cent) of the discussions in the two forums, 15 at Iltalehti and 4 at KaksPlus, all of which were analyzed through material-based content analysis (Tuomi \& Sarajärvi, 2002) and categorized according to the reactions and attitudes (expressed) towards to swine flu and the actions of the authorities.

\section{RESULTS}

In total 2264 comments were analyzed. The length of the discussions varied, the longest contained 1426 comments, whereas the shortest had only two. On average there were 119 comments per discussion. The majority of the discussions (57\%) lasted less than two weeks and were held between November and December 2009. The intensity of the interaction varied greatly. The one with the most comments lasted three months and attracted 28 comments per day, whereas another discussion lasting eight months contained only 12 comments.

It was not possible to calculate the number of different people participating, because many of them did not use a name or pseudonym, but were anonymous, and other individuals may have used several different pseudonyms at different times.

\section{Themes of interest}

Overall, the topics in the two forums were very similar. Three main topics of discussion emerged: 1 ) symptoms of the flu, 2) safety of the vaccine, 3) the epidemic, risk groups and its victims. Citizens wanted more information about the symptoms of the flu, how to recognize it, to hear about the experiences of infected people and to get advice in their personal situation. Vaccination was discussed intensely: citizens debated the positive and negative sides of getting vaccinated, and they were worried about side-effects, especially for pregnant women and small children. The ingredients of the vaccine provoked many comments. The fact that the vaccine was claimed to contain thiomersal and mercury caused speculations about its health risks. The rapid launch of the product 
onto the market made people wonder whether it had been fully tested. The third topic covered was the epidemic itself, risk groups and victims. Citizens pondered the situation of members of risk groups, such as those of pregnant, overweight and seriously ill people. Initiators mostly asked questions, wanting more information about the effects of the virus on their own personal health, and to share experiences about it. In fact, 10 of the 19 discussions started with a question. However, the initiators' point of view had no effect on the later comments of participants, and a wide variety of opinions and comments were posted in all the discussions.

\section{Attitudes towards authorities and vaccination}

The results show a clear variation in people's attitudes. Three main attitude types were visible: neutral, positive and negative, and these formed the three categories of the study. Within these categories, subtypes were identified which revealed deeper perceptions of the swine flu epidemic (see figure 1).

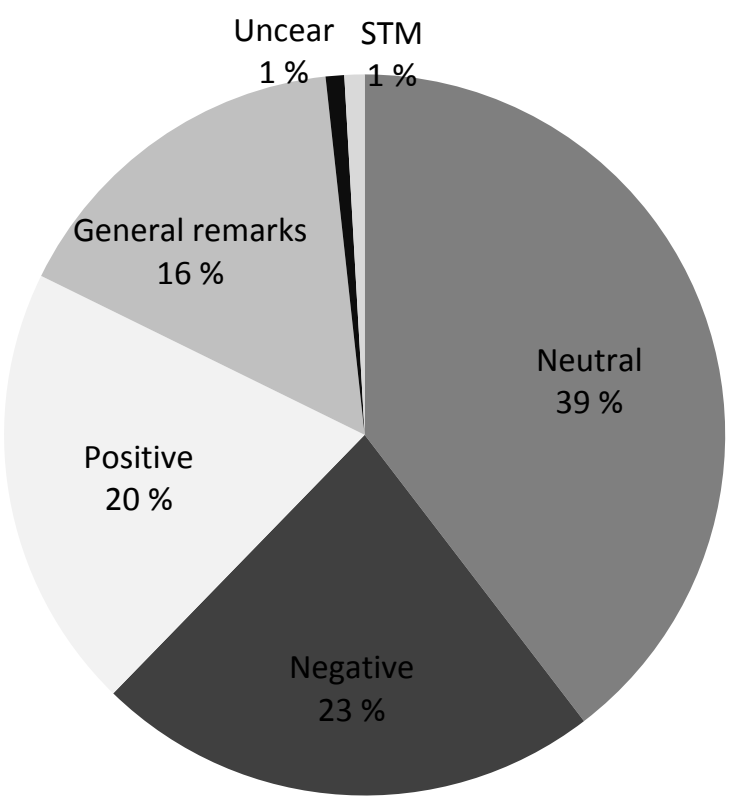

Figure 1. Attitude groups in the swine flu discussions $(N=2264)$.

Neutral comments accounted for 38 per cent of the discussions (see Figure 1). These comments contained no visible opinions or attitude towards the authorities, vaccination campaign or the epidemic in general. Many neutral comments provided information about swine flu and factors related to it. Those persons were called "information providers". 
"700 people have died of swine flu during this week all over the world. Altogether, over 5700 people have died since last April. In Europe the swine flu has been the cause of death of over 280 persons..."

Neutral participants also provided medical information and interpretations the validity of which may be difficult for citizens to assess. However, participants did not identify themselves as physicians.

"Adjuvant ASO3 is a so called oil-water based boosting element. It consists of skyalen, DL-alfatokopheryl and Polysorbate 80...”.

Again, others were asking for help. They wanted to know what the symptoms of swine flu were and how they differed from those of normal influenza. In addition, they felt they did not know enough about the vaccine and its chemical particles, and were worried about their own and their family's health. Also, news cited from foreign countries like Ukraine, Norway and Switzerland raised questions. This group of neutrals can be labelled as "thirsting for knowledge".

"There is mercury in the vaccine, but not in the adjuvant. What ingredients does the adjuvant have? Where can I find the specifications? Can anybody help me?"

“...Can somebody explain this to me? In Switzerland Glaxo and Novartis vaccines are available... What kind of vaccine will pregnant women get, if both of the vaccines have the adjuvant in them?

Many of the neutral comments expressed concern about the disease and its serious consequences. That was especially noticeable in the KaksPlus online forum, where 9.8 per cent of the comments expressed concern. In particular, pregnant women and persons with small babies and children were worried and afraid.

“...I'm afraid of the vaccine. Has anybody's child and especially a small baby been vaccinated? What kind of symptoms did that baby have?

Negative comments formed the second attitude category, with 22.7 per cent of the comments. Negative opinions were more visible (40 per cent) at Iltalehti than at KaksPlus (15.9 per cent). Citizens were critical of three different things: the vaccination, the authorities and the medical companies. These 'vaccination critics' perceived the vaccine to be more dangerous to human health than the disease itself and did not want to take the risk of being vaccinated. They emphasized the importance of vitamins in preventing the swine flu, and some seemed strongly to support the use of natural products. In particular, it was feared that the vaccine contained mercury and thiomersal, and these individuals did not believe the vaccine test results, which were published in the media.

“...Why should I bring my children to be vaccinated with a vaccine which has not been tested enough?..

“...Don't take the nano vaccine, which has not been properly tested”...

Behind such critical attitudes was distrust of the authorities and medical companies. Comments targeted at authorities such as STM, THL, the European Medicines Agency (EMEA) and WHO were openly hostile. THL in particular was accused of being corrupt, unreliable and "palming off" dangerous vaccinations to citizens. Some people believed that the whole epidemic had been deliberately created by medical companies in order to make money for themselves and their shareholders. Hostile comments levelled at the authorities were often highly emotional and included 
various internet links and online materials to support the arguments. The materials used included newspaper and tabloid articles (interpreted in a negative way) and blogs by other critical persons, YouTube nationwide swine flu portals, such as sikainfluenssa.org, and unidentifiable websites. Scientific articles and authorities' websites were also used (emea.org, ktl.fi, who.org), but all with a negative interpretation of the data. There was no difference in the content of the negative comments between the two forums. The same messaging style characterized both of them.

"Rokotusinfo has published information on its website and in the media about THL's financial connections with the vaccination producer GlaxoSmithKline....THL has tried to change the law so that children could be used in vaccine tests without the permission of their parents."

Positive comments (total 19.8 per cent) defended the vaccine and the authorities against the critical citizens. Either the comments were about the safety of the vaccine and its protective effect on humans, or about the professionalism and trustworthiness of the authorities and scientific research. 'Positive citizens' told about their personal experiences of getting vaccinated, without encountering any dangerous side effects, and especially emphasized the safety of the vaccine. They offered scientific research material in support of their argumentation and referred to the information disseminated by the authorities.

"I'm really happy that the vaccine REALLY works. Now I cannot be infected by the fatal swine flu".

The interaction between these three attitude groups was active. Both 'positive' and 'negative' citizens were discussing and justifying their opinions. Emotion-laden language was frequently used and others were accused of being "stupid"," narrow-minded" or "naïve". Neutrals mostly provided information and shared their own experiences. Some citizens (15.9 per cent) commented on their frustration at the poor quality and low level of the debate. Some comments were "off-topic", concentrating on details like typos in the text or making remarks which did not fit into any relevant category.

\section{STM as a debater}

STM took a minor role in the discussions as an active participant; STM started their intervention in December 2009, 7 months after the debate started. In 18 discussions STM contributed only one comment and in one discussion posted three comments. The fact that no authors were named, beyond the pseudonym 'STM-influenssainfo' (STM influenza-info), may have underlined the fact that it was an authority speaking. The messages gave information about the vaccine, its composition, safety, and repeated swine flu symptoms. Two of the authorities' comments included a direct message to a citizen (two positive comments), otherwise the nature of the text was informative and unemotional. STM did not initiate discussion, but reacted to already existing topics, tried to provide correct information for those critical of the vaccine and to answer questions. In four discussions STM's comment was the last one in the list and therefore it is not possible to evaluate its effects. In 3 of the discussions, citizens asked the authority direct questions but did not receive any answer, or the answers were incomplete, covering only part of the question. STM's comments inspired 
negative, even hostile comments in the majority of the discussions ( 58 per cent), either directly after the authority's comment or some comments later.

"How do you know that the vaccine gives high protection (referring to a person from STM)? The investigation has only just been started. The authorities' image is such that nobody knows anything about anything. Just guessing."

"Hey Babe! Don't you have real work and better things to do than sit here spreading propaganda in discussion forums?"

The most typical reaction of citizens was to quote STM's comments and criticize them, to ask for more information, better proof and more objective research results. In three cases STM's comments did not cause any visible reactions.

\section{CONCLUSIONS}

Based on the data it can be stated that for the authorities, the swine flu case was not a success, whereas for critical bloggers, anti-vaccination groups, NGOs and representatives of natural products it was a great success. The swine flu debate is evidence of a radically changed communication environment, of how online issues arenas can complicate a prevailing crisis. Figure 2 visualizes the most powerful voices in the swine flu issue arena, and also shows those who were left outside that arena. Moreover, the forums challenge authorities' resources as well as traditional, formal communication. The results show that the resources available for the credible intervention of the authorities were inadequate, and that online public opinion was mostly against the vaccine. The comments by STM represented only 1 per cent of the total comments, and through such a miniscule effort authorities cannot change people's attitudes or even provide the necessary information. The negative and disrespectful reactions to STM's presence in the forums clearly showed that citizens did not believe in or value the information provided by the ministry, which also shows reluctance to believe what the authorities say. Affecting people's attitudes and behaviour is overall a challenging task, and the Internet makes it even more difficult, as people communicate behind pseudonyms or anonymously, and customary rules of interaction are not followed. Then again, trust towards an institution can be created online, if the representative of the institution is perceived as trustworthy and the messages are targeted for the stakeholders (Bekmeier-Feuerhahn \& Eichenlaub, 2010).

The fact that an intervention is undertaken by an authority is to be viewed positively, as many authorities hesitate to become involved in social media. However, STM's intervention only began when the epidemic had already reached its peak in Finland, in November 2009. With an earlier and wider intervention STM could have become one of the active players in the arena and provided answers to the numerous questions asked in the forums. In the event, questions targeted at STM were left unanswered and no real dialogue was established. 


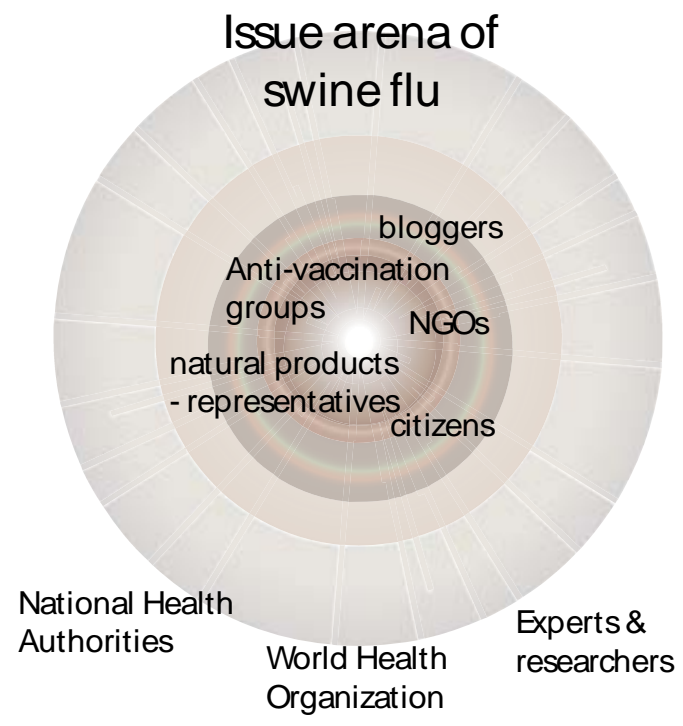

Figure 2. The online Issues Arena of the swine flu debate in Finland, autumn 2009.

Figure 2 visualizes that the central players online were individual citizens, bloggers, NGOs, antivaccination groups and representatives of natural products. The national health authorities, WHO and experts and researchers were left outside the discussion. In this study the traditional media arena was not investigated, but on the basis of the number of media releases, the authorities may be assumed to have had a stronger presence there.

\section{DISCUSSION}

Issue arenas are identified as new arenas for communication, and a sign that organization-centred communication is over (Luoma-aho \& Vos, 2010), as the traditional organization-centred view of communication does not accurately describe the organizational environment of today. Continuous environmental monitoring has increased in importance, as various stakeholders are able to act through, for example, various real time media. The changing dynamics of communication call for careful monitoring, especially during periods of heightened risk and crisis. The case study on swine flu illustrates that issue arenas are home to a variety of players and that speed has become a crucial element of success in opinion-forming. If monitoring is ongoing and an issue is identified early, public organizations have a better chance of becoming one of the actors on stage, whereas slow reactions may lead to them having just a place in the audience.

Although the swine-flu case represents only one issue, the study has several implications for practice. First, online issue arenas offer excellent sources for monitoring topics of interest to citizens, providing information which can be used in planning official communication. Second, influencing citizens' opinions remains a challenge. Online, most people have strong opinions and 
they are not willing to change them. Third, entering the arena as an authority has to be considered carefully and planned well in advance, taking into account who will be considered as credible sources and whether these should be mentioned as persons rather than just using the name of the organization. If the aim is to affect health behaviour such as convincing individuals of the importance of a vaccination, the authorities need to have enough resources in order to initiate real dialogue. Failing to prepare well or entering too late into a dialogue can result in having no impact or worse, even negative consequences. Moreover, emotion-filled arenas call for new rhetorical strategies to complement the logical arguments.

Moving from organization-centred thinking to issue arenas will also have effects on the practice of communication during crises. Practitioners should try to identify the different issues arising from and related to the specific crisis, while increased monitoring will mean keeping ahead in both the physical, traditional issue arenas as well as the new, virtual issue arenas. New tools and more research are needed to better understand this change. Future studies should focus on the kinds of strategies needed to find a balance in a diverse and dynamic external environment as well as on how to best identify the relevant issue arenas before and during a crisis. Since this study focused on one country, a global comparison could be the next step.

\section{Acknowledgements}

The present study partially received funding from the European Community's Seventh Framework Programme (FP7/2007-2013) under grant agreement no. 217889.

\section{References}

Avery, E. \& Kim, S. (2009), Anticipating or precipitating crisis? Health agencies may not be heeding best practice advice in avian flu press releases. Journal of Public Relations Research, Vol. 21 No. 2, pp. 187-197.

Bekmeier-Feuerhahn, S. \& Eichenlaub, A. (2010), What makes for trusting relationships in online communication? Journal of Communication Management, Vol. 14 No. 4, pp. 337-355.

Cammaerts, B. (2007), Citizenship, the public sphere and media. In Cammaerts, B. and Carpentier. N. (Eds), Reclaiming the media: Communication Rights and Democratic Media Roles. Vol. 3, ECREA. Intellect: Bristol. Online http://www.intellectbooks.co.uk/books/viewBook,id=4564/ (accessed 1.12.2010).

Cheney, G. and Christensen, L. (2006). What should public relations theory do, practically speaking? Journal of Communication Management, Vol. 10 No.1, pp.100-102.

Christensen, L., Morsing, M. \& Cheney, G. (2008), Corporate communications; convention, complexity, and Critique. Sage: London.

Christensen, L., Torp, S., \& Firat, F. (2005), Integrated marketing communication and postmodernity: an odd couple? Corporate Communications: An International Journal, Vol. 10 No. 2, pp. 156-167.

Coombs, W.T. (1999), Ongoing Crisis Communication: Planning, Managing, and Responding, Thousand Oaks, CA: Sage. 
Coombs, W. T. \& Holladay, J. S. (2008), Comparing apology to equivalent crisis response strategies: Clarifying apology's role and value in crisis communication. Public Relations Review, Vol. 34 No. 3, pp. 252-257.

Flynn, T. (2006), A delicate equilibrium: balancing theory, practice and outcomes. Journal of Public Relations Research, Vol 18 No 2, pp.191-201.

Freeman, R.E. (1984), Strategic Management: A Stakeholder Approach. Pitman: Boston.

Goffman, E. (1959), The presentation of self in everyday life. New York: Doubleday.

Goffman, E. (1974), Frame analysis. Boston, MA: Northeastern University Press.

Gower, K. (2006), Public relations research at the crossroads. Journal of Public Relations Research, Vol 18 No 2, pp. 177-190.

Grunig, J. (2006), Furnishing the edifice: ongoing research on public relations as a strategic management function. Journal of Public Relations Research, Vol 18 No 2, pp. 151-176.

Hallahan, K. (1999), Seven models of framing; implications for public relations. Journal of Public Relations Research, Vol 11 No 3, pp. 205-242.

Heath, R. (1997), Strategic issues management. Sage: Thousand Oaks.

Heath, R. (2006), Onward into more fog; thoughts on public relations' research directions. Journal of Public Relations Research, Vol 18 No 2, pp. 93-114.

Howell, G., \& Miller, R. (2006), How the relationship between the crisis life cycle and mass media content can better inform crisis communication. PRism Vol. 4 No. 1, pp 1-14. Available at: http://www.prismjournal.org/vol4_1.html

Johansson, K. (2007), Goffman's sociology: An inspiring resource for developing public relations theory. Public Relations Review, Vol 33 No3, pp. 275-280.

Karagianni, K. S., \& Cornelissen, J. (2006), Anti-corporate movements and public relations. Public Relations Review, Vol. 32 No. 2, pp. 168-170.

Loewenstein, G., Weber, E., Hsee, C., \& Welch, E. (2001), Risks as feelings. Psychological Bulletin, Vol 127 No 2, 267-286.

Luoma-aho, V.\& Vos, M. (2010), Towards a more dynamic stakeholder model: acknowledging multiple issue arenas. Corporate Communications, Vol 15 (3), pp. 315-331.

Luoma-aho, V.\& Vos, M. (2009), Monitoring the complexities: Nuclear power and public opinion. Public Relations Review, Vol 35 (2), pp-. 120-122.

Miel, P. and Faris, R. (2008), News and Information as Digital Media Come of Age, Overview 2008. The Berkman Center for Internet \& Society at Harvard University: Cambridge, available at:

http://cyber.law.harvard.edu/sites/cyber.law.harvard.edu/files/Overview_MR.pdf (accessed 1.12.2010).

Millar, D. P and Heath, R. L. (2004), A Rhetorical Approach to Crisis Communication: Management, Communication Processes, and Strategic Responses. In Millar, D. and Heath, R. L. Responding to Crisis. A Rhetorical Approach to Crisis Communication. New Jersey: Lawrence Erlbaum Associates, Inc

Mitchell, R., Agle, B. and Wood, D. (1997), “Toward a theory of stakeholder identification and 
salience: defining the principle of who and what really counts", Academy of Management Review, Vol. 22 No. 4, pp. 853-86.

Pavlik, J. (1987). Communication. What research tells us. Sage: London.

Reynolds, B. (2006), Crisis and emergency risk communication. Pandemic influenza. Available at: http://www.bt.cdc.gov/cerc/pdf/CERC-PandemicFlu-OCT07.pdf (accessed February 23, 2010).

Reynolds, B. and Seeger, M. (2005), "Crisis and emergency risk communication as an integrative model", Journal of Health Communication, Vol. 10 No. 1, pp. 43-55.

Roper, J. \& Toledano, M. (2005), Taking in the view from the edge: Issues management recontextualized. Public Relations Review, Vol 31 No 4, pp. 479-485.

Rosa, E. (2003), Metatheoretical foundations. In Pidgeon, N., Kasperson, R.E. and Slovic, P. (ed.), The Social Amplification of Risk, pp. 47-79. Cambridge: Cambridge University Press.

Rosenthal, U. \& Kouzmin, A. (1997), Crises and crisis management; toward comprehensive government decision making, Journal of Public Administration Research and Theory, Vol. 7 No. 2, pp. 277-304.

Rowan, K. (1991), Goals, Obstacles, and Strategies in Risk Communication: A problem-solving Approach to Improving Communication About Risks. Journal of Applied Communication Research, Vol. 19 No. 4, pp. 300-329.

Sumser, J. (2001), A guide to empirical research in communication; rules for looking. Sage: Thousand Oaks.

Sutcliffe, K. (2001), Organizational environments and organizational information processing. In Jablin, F. \& Putnam, L., The new handbook of organizational communication; advances in theory, research and methods, London, Sage.

Tuomi, J. \& Sarajärvi, A. (2002), Laadullinen tutkimus ja sisällönanalyysi. Kustannusosakeyhtiö Tammi: Helsinki. (In Finnish. Qualitative research and content analysis).

Vos, M. \& Schoemaker, H. (2006), Monitoring the public perception of organisations. Boom, Amsterdam.

Wan, H. \& Schell, R. (2007), Reassessing corporate image; an examination of how image bridges symbolic relationships with behavioural relationships. Journal of Pubic Relations Research, Vol 19 No 1, pp. 25-45.

Weick, K. (2001), Making sense of the organization. Blackwell: Malden.

Welser, H. D., Gleave, E., Fisher, D. and M. Smith. (2007), Visualizing the Signatures of Social Roles in Online Discussion Groups. Journal of Social Structure, Vol 8 No 2, pp.1-32.

Wilson, L. (2001), Relationships within communities. Public relations for the new century. In Heath, R. (Ed.) (2001). Handbook of public relations. Sage: Thousand Oaks, pp. 521-527.

Wu, X. (2007), Stakeholder identifying and positioning (SIP) models: From Google's operation in China to a general case-analysis framework. Public Relations Review, Vol 33 No 4, pp. 415-425. 